\title{
A Genealogical Analysis of Information and Technics
}

\author{
J.J. Sylvia IV (1)
}

Citation: Sylvia IV, J.J. A Genealogical Analysis of Information and Technics. Information 2021, 12, 123. https://doi.org/10.3390/ info12030123

Received: 11 February 2021

Accepted: 9 March 2021

Published: 12 March 2021

Publisher's Note: MDPI stays neutral with regard to jurisdictional claims in published maps and institutional affiliations.

Copyright: (C) 2021 by the author. Licensee MDPI, Basel, Switzerland. This article is an open access article distributed under the terms and conditions of the Creative Commons Attribution (CC BY) license (https:/ / creativecommons.org/licenses/by/ $4.0 /)$.
Department of Communications Media, Fitchburg State University, Fitchburg, MA 01420, USA; jsylvia3@fitchburgstate.edu

\begin{abstract}
This paper explores how the concepts of information and technics have been leveraged differently by a variety of philosophical and epistemological frameworks over time. Using the Foucauldian methodology of genealogical historiography, it analyzes how the use of these concepts have impacted the way we understand the world and what we can know about that world. As these concepts are so ingrained in contemporary technologies of the information age, understanding how these concepts have changed over time can help make clearer how they continue to impact our processes of subjectivation. Analysis reveals that the predominant understanding of information and technics today is based on a cybernetic approach that conceptualizes information as a resource. However, this analysis also reveals that Michel Foucault's conceptualization of technics resonates with that of the Sophists, offering an opportunity to rethink contemporary conceptualizations of information and technics in a way that connects to posthuman philosophic systems that afford new approaches to communication and media studies.
\end{abstract}

Keywords: information; technē; technics; Michel Foucault; subjectivation; resource doctrine of information; genealogy; media genealogy; media archaeology

\section{Introduction}

"Information is a term that does not like history."-John Durham Peters [1].

Often the origin of the concept of information is mistakenly sourced back to its use in 1949 by Claude Shannon's and Warren Weaver's [2] A Mathematical Theory of Communication and the prolific field of cybernetics generated by this work. While Shannon's conceptualization of information is certainly relevant and closely linked with the ideas of information and data that have proliferated through their now-common usage in relation to computers and networks, the concept has a much longer history that is closely integrated with the history of western philosophy, specifically as it relates to metaphysics and epistemology. Although this genealogy has been traced by authors such as Peters [1], Capurro [3], and Behrenshausen [4], it has rarely been connected to a genealogical exploration of technics at the same time. A more detailed examination of these genealogies in tandem offers the possibility of rediscovering problem-spaces that could open up alternatives to the resource doctrine of information, which conceives of information predominantly as a resource [5]. Behrenshausen [4] extends this analysis by emphasizing the ways in which a "resource doctrine of information" authorizes a very specific kind of subject that aligns closely with the Enlightenment-era perspectives on the individual centered on reason, consciousness, and rights. Drawing on Lawrence Grossberg's notion of the problem-space as a set of tensions related to a particular issue, Behrenshausen argues that the problem-space of information also makes apparent the problematic notion of agency, because the Enlightenment-era subject bound by a resource doctrine of information is limited to particular ways of acting as an agent.

By rethinking the concept of information, a genealogical analysis will be able to help one better understand the current problem-space of information in order to create and arrange a new problem-space. Such a creation offers the opportunity to think about information and big data outside of the resource doctrine of information in ways that 
escape the predominately profit-oriented capitalist approaches. Furthermore, the concept of information has not been systematically linked with that of technology in such an analysis. The relation of these two concepts over time opens new ways of thinking about each of the concepts and generates different approaches of understanding what it means to be human, or as Bernard Stiegler [6] argues, the "possibilization" of the past.

Peters [1] traces the term "information" back to fourteenth-century use of the Latin informare (to instruct) and informatio (an idea, instruction, concept, or doctrine). Capurro [3] offers a more detailed exploration of informatio, attributing to it two meanings, one metaphysical and the other epistemological: "'the action of giving a form to something material' as well as 'the act of communicating knowledge to another person,'" (128). The metaphysical definition of giving form to something material is linked closely to Aristotle's notion of hylomorphism that conceives of being as created by the combination of matter and form [7]. These uses, Peters explains, can be seen in Virgil's description of Cyclops and Vulcan hammering out lightning bolts for Zeus and Tertullian's description of Moses as one who molds people. Through this understanding, similar concepts can be traced back to the Greek philosophic concepts of eidos and morphé through the work of authors such as Cicero, St. Augustine, and Thomas Aquinas. For example, "Augustine calls in De trinitate the process of visual perception 'the moulding of sensory perception' (informatio sensus) (trin 11, 2, 3) pointing to the Platonic (Theaet. 191d) and Aristotelian epistemological metaphors (De an. 424 a 17) of the impression (imprimitur) of a ring seal into wax, i.e., into memory," [2] (p. 128). Aquinas similarly links Aristotle's hylomorphism to the process of 'in-forming' matter [1].

The genealogy developed in this paper, while not exhaustive, aims to trace the relations of the concepts of information and technics through a number of major theorists in the history of philosophy as a way to propose a new relation of these concepts. Following the Deleuze/Guattari project of geophilosophy, I evaluate these concepts not in order to determine whether or not they fit within a history of truth, but rather to evaluate their consistency, the affects they produce, and the politics which they make possible, in order to redeploy the concepts on a new plane [8]. Understanding the genealogical inscription of these concepts will enable their reconfiguration in light of the contemporary problem of capitalist capture of the subject. There are real-world problems related to big data and the subject, and their capture by systems of capital. Current conceptualizations of information and big data within the resource doctrine have offered limited solutions to these challenges such as privacy and anonymization, which have lost their effectiveness in the age of big data. Such limitations create the need for a new approach.

This genealogy will begin with the founding of Western philosophy in the dispute between the Sophists and Socrates, contrasting their understandings of eidos and techne. It will then trace the changing meanings of these terms as they become solidified in Western philosophy through the works of Plato and Aristotle. Although some religious philosophers use these concepts during the Middle Ages, the next significant shifts in meaning occur at the dawn of the Age of Enlightenment. I analyze the development of eidos and techne in the works of rationalist René Descartes and empiricist Francis Bacon. Next, I trace the development of these terms in the work of David Hume, because the shifts he makes in his use of these terms will have important implications for the later work of Gilles Deleuze. Next, I show how the cybernetic approach understands information as a form of control, before finally exploring the Foucauldian approach that understands these concepts in terms of subjectivation.

There are two developmental threads that I will follow. The first is the shift in the way that the term eidos is understood as it changes from form to information. The second is the separation of the terms technique and technics from the Greek techne as a way of narrowing their meaning to limit it to only practical abilities divorced from the aspect of wisdom present in techne. With Michel Foucault, the term technology is used in a way that makes clear its role in wisdom, moving it closer to the original Greek usage. An important caveat is that the terms techne/technics/techniques/technology have not always been clearly 
separable. Some of the terms only arose in much later time periods to attempt to make a distinction. Where there may be some slippage between these terms, I have tried to stay true to their use in context of a particular author.

\section{Materials and Methods}

In this paper I use a Foucauldian genealogical historiography of the concepts of information and technics as the primary method. This method is concerned with "the processes, procedures and apparatuses by which truth and knowledge are produced," [9]. I trace how various philosophical and epistemological systems have leveraged these concepts, especially as they relate to one another within those systems. These changes are not linear and are often subject to disruptions and discontinuities across time. However, a genealogical analysis of these concepts can make clear how they have been used in the modern information era and leveraged for use by contemporary technological practices and developments in quantum information and computing [10].

Additionally, the approach connects to work on media genealogy, which aims to add both politics and processes of subjectivation to media archaeology practices [11,12]. In particular, I argue that by better understanding the genealogy of information and technics, one can better understand how these concepts contribute to contemporary processes of subjectivation as they are deployed in the development of informational technology. This methodology, then, employs an analysis of the works of prominent philosophers who shaped the conceptual understanding of information and technics. This analysis is undertaken both to better understand the present moment and to search for new and/or forgotten ways of thinking about technology and information differently $[8,9,13]$.

\section{Results}

The results of the genealogical analysis are shared below. Figure 1 provides a timeline diagram that highlights the main uses of these concepts over time. Each section offers a genealogical analysis of the two terms as they were used in the major philosophic works of that era, as well as a comparing and contrasting that use to past systems, where appropriate. Particular theories were chosen based on whether or not they addressed the concepts of information and technics and if these concepts differed from past uses.

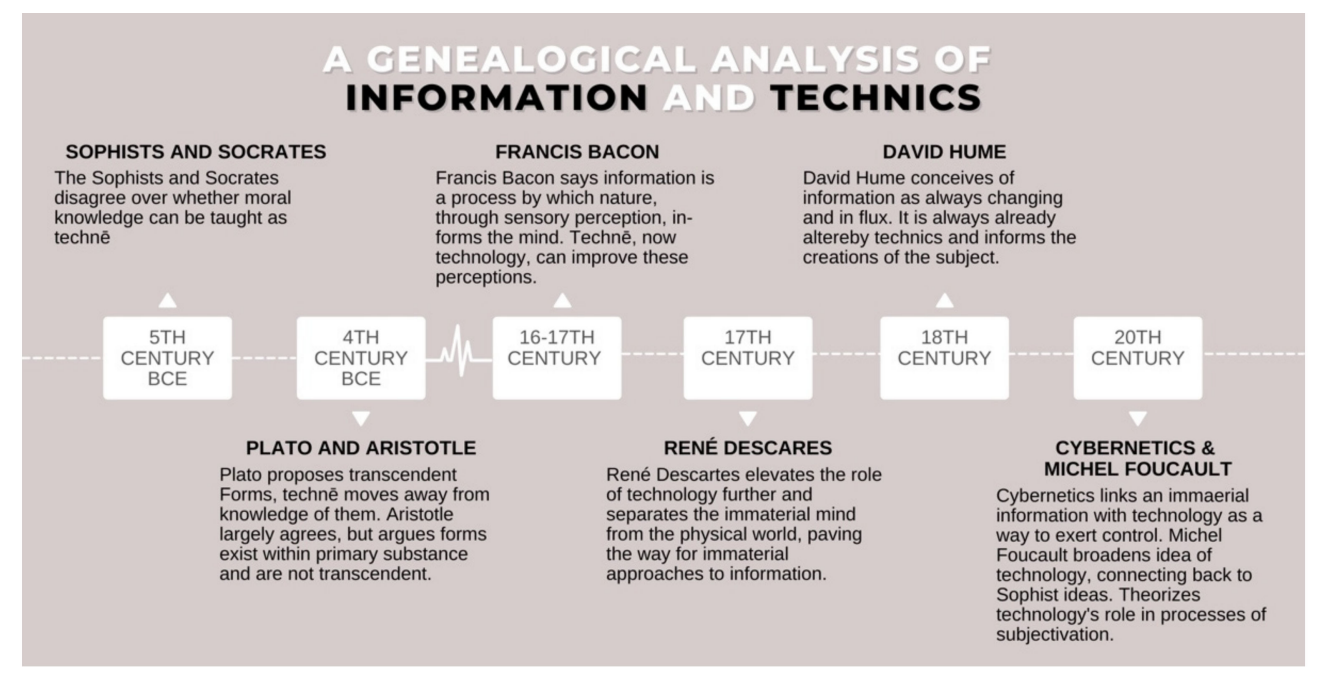

Figure 1. Overview of use of information and technics in major philosophic systems.

\subsection{The Sophists and Socrates}

Bernard Stiegler [6] locates the beginning of Western philosophy with its separation of techne from épisteme . Western philosophy arose as a different way of thinking at least in part due to the 5th century BCE dispute between Sophists and those who would later come to be known as "philosophers," such as Socrates and Plato. Much of this disagreement 
centers around the meaning of and importance of techne. The Dissoi Logoi, one of the longest surviving Sophist texts that was possibly authored by a student of Protagoras, addresses a man equipped with skills (techne $)$ who is involved in an argument and knows how to argue correctly [14]. Although the main argument of this text appears to offer two contradictory positions, its use of techne can be understood as an important skill for argumentation in attempting to speak correctly, acknowledged by both Sophists and philosophers as an important part of achieving logos, or knowledge. Cicero, a later rhetorician, uses technē in a similar way, explaining that he was "educated by Archias in tecniques [sic] such as writing whose aim is to educate or 'in-form' young people in order to become a true human being (quibus aetas puerilis ad humanitatem informari solet) (Arch. 3)" [3] (emphasis added, p. 128). This is similar to the connection Stiegler [6] makes between sophistic writing and the "tutoring" of the citizen (p. 13). The word 'technique' quoted above is translated from the Latin artibus, from the root ars, which could be more literally translated as 'art'. However, this distinction also harkens back to the Greek techne, which has been translated in a myriad of ways including skill, craft, technique, and art. Here Cicero is linking technique (Latin ars or Greek technē) to its ability to in-form a person, similar to its use in Vergil. This specific linking of techne to the in-forming of a human being is rare in this history of philosophy. The Sophists charged their students fees in return for teaching them how to use argumentation to support a particular position. This method can be seen in the few fragments of Protagoras' writing that survive, mainly through references in others' work. From these fragments, there are two primary arguments for which Protagoras is well known. First, he argues that man is the measure of all things, which has largely been taken as a highly subjective and anthropocentric argument. Second, Protagoras argues that there are always two arguments opposed to one another, and that one can make the weaker argument seem stronger [15]. Both of these arguments reflect Protagoras' belief that there is no single perspective that is absolutely correct, because truth depends on the frame of reference. This belief can be viewed as a direct contradiction to Socrates' quest to discover essential definitions for complex ideas such as justice and holiness in his conversations with Athenian citizens. For example, in the Euthyphro dialogue, Socrates, in trying to get Euthyphro to explain what holiness is, says: "I wanted you to tell me what is the essential form of holiness which makes all holy actions holy" [16] (6d). While Socrates seeks this essential form of holiness that can be used to judge any particular action as either holy or unholy, a Sophist would reject such a possibility and instead argue that the holiness or unholiness of any action is dependent on the context of a specific situation, much as Euthyphro tries to do in his first definition of holiness, which is rejected by Socrates. What is at stake in this disagreement is whether or not moral knowledge can be taught as a techne. . David Roochnik [17], in undertaking a thorough analysis of the Greek use of techne, argues that Sophists believe such teaching is possible, while Socrates, at least as portrayed in the dialogues written by Plato, does not. This view is substantiated by Socrates in his recounting of his discussion with Protagoras in the dialogue of the same name: "I know that if we could be clear about that, it would throw the fullest light on the question over which you and I have spun such a coil of argument, I maintaining that virtue was not teachable and you that it was" [16] (360e-361). To see why this distinction regarding techne is important and how it relates to the Greek concept of eidos as it pertains to information, one must further explore Plato's metaphysics.

\subsection{Plato's Transcendent Forms}

Plato's work in the 4th century BCE is situated historically as both a continuation of Socrates' project aimed at finding essential definitions and a response to the Sophists' emphasis on the subjective nature of truth. In response to this subjectivity, Plato metaphysically formalizes Socrates' search for essential definitions through his creation of the concept of Forms or Ideas (eidos). These Forms should be understood as a type of pattern, template, or blueprint in which all of reality must partake. This can be seen clearly in the language above that Plato has Socrates speak in the Euthyphro: "I wanted you to tell me 
what is the essential form of holiness which makes all holy actions holy" [16] (6d, emphasis added). The Forms have several characteristics that are identifiable through dialogues that include Euthyphro, Phaedrus, Symposium, Republic, Parmenides:

1. Perhaps most importantly from a metaphysical perspective, they exist apart from particulars in the world. They are changeless, eternal, incorporeal, and accessible to reason but not senses. Beauty is the only exception, because it is available to the senses and actually begins the process of understanding the Forms.

2. They cause particular things to be what they are. For example, the Form of Justice causes an act to be just. There are several theories as to what type of causation exists in this representation [18]. One theory argues that particulars participate in Forms, though how this participation works is never made entirely clear. Another theory is that particulars imperfectly imitate the Forms, though this is problematic because it is not clear how an imitation of an incorporeal Form can take on corporeality, which is a key problem for dualist ontology, as Deleuze [19] argues in Difference and Repetition. The lack of a clear explanation for this causation will be an important factor in Aristotle's reformulation of Plato's theory of Forms.

3. Particular things are in flux, but Forms are static. Plato argues that if there is only flux, knowledge is impossible, therefore the Forms must exist.

4. The Forms have the characteristics that they give to particulars, i.e., the Form of Beauty is itself beautiful.

5. Every Form is defined by an essential definition, which recalls the Socratic project.

6. There are different types of Forms, which means that there must also be a Form of Forms. For Plato this is the Form of Good. It is beyond being and nourishes everything.

7. One Form may contain others. For example, the Form of Animal contains the Forms of both Bird and Frog.

These characteristics of the Forms thus lay the groundwork of all of Plato's theory of metaphysics, clearly identifying the Forms as a transcendent other entity that is separate from the everyday reality in which humans find themselves. These metaphysical characteristics of Forms, once understood, can also be seen to directly impact Plato's epistemology.

Plato [16] explains his epistemology most clearly through his metaphor of the divided line. On one end of the divided line there is the visible realm that consists of opinion and reflects a world of constant change and flux. One has access to the visible realm through their senses such as vision and hearing. Understanding is a bridge between this visible realm and the intelligible realm, where the Forms are located. Knowledge and reason allow us to know the Forms, but this knowledge is attainable only through the mind rather than the senses. This epistemology has important consequences for the relationship of the techne to the Forms. Both art and craftsmanship, as multiple interpretations of techne, serve to actually move one further away from the knowledge of the Forms. It is not simply the content of the art, such as poetry, that is problematic, but also the nature of what techne attempts to do. The form that Plato criticizes is mimesis, which translates to the English "mimesis" or "imitation." Plato uses the Iliad as an example of what exactly he means by imitation:

You know then that as far as these verses,

Additionally, prayed unto all the Achaeans, Chiefly to Atreus's sons, twin leaders who marshaled the people,

the poet himself is the speaker and does not even attempt to suggest to us that anyone but himself is speaking. However, what follows he delivers as if he were himself Chryses and tries as far as may be to make us feel that not Homer is the speaker, but the priest, an old man. [16] (Republic, 393-b).

This imitation is problematic because it masks the truth. Plato believes the Forms are the real Truth, while the reality that one typically knows is already once removed from that, and any work of imitation would then be two times removed from Truth. Similarly, if a wood worker were to craft a chair, this is merely a poor imitation of the Form of the chair 
because it only participates imperfectly in the ideal Form of the chair. It is only through the act of reason, and not that of techne, that one gains knowledge of the Forms. This is in contrast to the Sophists, for whom reason itself is a form of techne.

Difference from the Ideal Form is thus negatively understood. Plato sees actual things, and even worse, representations of actual things, as mere simulacra of their Ideal Forms. N. Katherine Hayles [20] calls this the Platonic backhand and forehand, explaining how this ontological move allows one to distinguish between information and materiality even now:

They share a common ideology-privileging the abstract as the Real and downplaying the importance of material instantiation. When they work together, they lay the groundwork for a new variation on an ancient game, in which disembodied information becomes the ultimate Platonic Form. If we can capture the Form of ones and zeroes in a nonbiological medium-say, on a computer disk-why do we need the body's superfluous flesh? (p. 11)

Hayles is critiquing some of the common versions of cybernetics that have arisen since the 1940s and have retained this Platonic dualism, upholding an idealist conceptualization of information. Plato believes that techne move us further away from the eternal Forms, and thus should be abandoned for a focus on the mind that seeks to know the Forms through the intellect. Although Aristotle also understands techne as something that interferes with the work of the mind, he takes a much different metaphysical stance on the nature of forms.

\subsection{Aristotle's Hylomorphism}

Aristotle, one of Plato's students, critiqued and extended his philosophic work. For Aristotle, also writing he in the 4th century BCE, Platonic Forms are not necessary to explain the nature of reality or the way in which we come to know that reality. Most concretely, we can see this in the case of a producer, such as an artist or a seed, which can cause forms in matter [7] (Metaphysics). As producers, we move material into a form. Aristotle argues that there is no pure form without material, and pure matter does not exist without form. Although Aristotle is using the same term as Plato, eidos, it means something that is entirely different metaphysically. Rather than giving metaphysical priority to Forms, Aristotle instead focuses on what he calls individuals, which are the primary substances of reality and can be predicated in ten basic ways: essence or secondary substance, quality, quantity, relation, place, time, position, state, acting, and being acted upon (Metaphysics). Without any one of these predicates, we could not properly discuss any particular thing, because it is through these predications that we are able to identify individual things.

Aristotle [7] expands on this system in his Metaphysics, where argues that there can be no science of individuals, though science can be applied to them, such as it is with medicine. Individual things are the primary substance. The secondary substance is the group they fall into, the patterns or forms within things. To determine the secondary substance, Aristotle uses genus and differentia. For example, man is in the genus animal, but we look to see what separates him from other animals (rationality, Aristotle argues). We can continue to find differences between things and break them down into smaller categories until finally we come upon things with no differences between them. Here we arrive at secondary substance. The last differentia will be the substance of a thing and its definition. One potential problem with this approach is that it is possible to narrow down individuals through differences all the way back to the individual level, such that determining where to stop generating differences is in some way arbitrary, blurring the distinction between primary (individuals) and secondary (form) substance.

Matter for Aristotle is uncreated, ungenerated, and eternal, in much the same way that Forms are for Plato. It is, simply put, what individual things are made of, or that which is given shape and structure by form. For example, the matter of a boat is wood: its form is the design the boat builder realizes in the wood. We can also see through this example that form and matter cannot actually exist separately, although we can distinguish them in analysis. The metal silver is a matter that can be given a variety of forms such as a fork, spoon, bracelet, or ring. Through these examples we see that these forms are 
not external in the way that they were for Plato; instead being is seen as a compound of form and matter. The form informs matter. This understanding of the coupling of form and matter later comes to be called hylomorphism in an 1818 letter written by Friedrich Schleiermacher [21]. Aristotle utilizes this coupling to explain how both change and stability can co-exist. Change does not mean something comes from nothing. Forms and matter cannot change by themselves, but the way that they combine can be changed. If the combination of form and matter is altered, then there is change rather than stability during the time that the combination is altered. Though it will be critiqued for its hylomorphic nature, this emphasis on ontological change rather than the eternal stasis of Forms will be important for the model of coming into being, or becoming, for Gilbert Simondon and Gilles Deleuze. Most notably, Aristotle inserts the human as a mediator between sense and form, which constructs a system of inductive logic [22].

Much like Plato, Aristotle places a low value on techne,; however, his reason for this is based on his system of ethics rather than metaphysics. In the Nichomachean Ethics, Aristotle explains that the good life is achieved through excellence of character, which sets the correct goals, and practical wisdom, which determines the means for achieving those ends. It is this practical wisdom that is most important for achieving the good life. Yet, even more important than this is theoretical wisdom, which consists of understanding how reality works. Aristotle explicitly lays out the hierarchy of wisdom: " ... the man of experience is thought to be wiser than the possessors of any perception whatever, the artist wiser than the men of experience, the master-worker than the mechanic, and the theoretical kinds of knowledge to be more of the nature of wisdom than the productive" [7] (Metaphysics 981b-30). Techne appears near the bottom of the list, while wisdom is at the top. He further argues that artisans have traditionally been slaves or foreigners, and the best forms government will not permit them to be citizens [7] (Politics 1278a).

For Aristotle, then, the relationship between form and techne is almost identical to that of Plato. They both believe that true knowledge comes from understanding the nature of reality and grasping how things work. They also both believe that techne is not helpful in developing this knowledge and should, by and large, be relegated to those not interested in the intellectual life. Indeed, the only real difference is the ontological status of the forms. Whereas Plato sees Forms existing as part of a transcendent external realm, Aristotle sees forms as existing within primary substance as part of a coupling of form and matter.

\subsection{Francis Bacon and Sense Information}

With Francis Bacon's shift toward empiricism in his work spanning the late 1500s and early 1600s, the concept of information takes an important turn, as it was deployed to describe the actual process of sensation in which nature in-forms the senses [1]. As mentioned above, although there is some use of the terms eidos and techne during the Middle Ages, they reflect the work of Plato and Aristotle closely and there was not a significant change in their use until the beginning of the Age of Enlightenment. Bacon's use of the concept of information represents a shift away from the metaphysical usage of the term as it was leveraged by either Plato or Aristotle, while in some ways aligning more closely with Sophist rhetorical traditions that emphasized the epistemological sense of the term. Whereas for both Plato and Aristotle, form was something that helped shape nature, or reality, it loses this role within Francis Bacon's [23] system of empiricism, published in 1620. Eidos instead becomes an active process of in-forming. This draws on the epistemological emphasis of the Sophists while at the same time extending Aristotle's insistence on change. Thus, it is with Bacon that we see the shifting usage away from eidos as a form toward in-formation as a process by which nature, through sensory perceptions, shapes the human mind. In terms of John Locke's empiricism, we might say that the world informs, or impresses onto the blank slate that is the human mind at birth. Although Plato's Forms existed in a transcendent realm and Aristotle's existed in nature, both existed somewhere in the world, broadly defined. With empiricism, information is being shifted toward the human mind via the senses [1]. However, as we will see, Bacon ultimately ends up with a 
transcendent metaphysical version of forms and a method that aims primarily at learning to manipulate the contingent forms of nature; this is the first system within philosophy proper that allows for the possibility that nature also informs the human.

For Bacon's empiricism, information is the raw data that needs to be interpreted and understood through reason: "The information of the sense itself I sift and examine in many ways. For certain it is that the senses deceive; but then at the same time they supply the means of discovering their own errors. The sense fails in two ways. Sometimes it gives no information, sometimes it gives false information." [23] (p. 24). To correct the difficulties with the senses, Bacon uses not instruments, but rather experiments, because their subtlety is greater than that of the senses. The central notion which ties together reason and science is method, or rules toward the direction of the mind, by which is meant logic. Bacon advocates for the role of inductive logic, as opposed to others such as Peter Ramus, who, a few years earlier argued that deductive logic plays this role. He develops a method of science that aims to systematically get rid of human biases by doing machine work that carries out its processes algorithmically. However, within a system of deductive logic, if it were possible to collect all of the information about everything in existence, then each instance would be unique and classified by itself; therefore no generalization would possible. This is similar to the problems with Aristotle's system of categorization.

Bacon instead argues for a method which is made better through the use of techne, understood by Bacon as the use of technology. In other words, senses give us information, but it is the techne that helps us find the form. We can aid sight through tools that enable us to see things not otherwise visible because they are too small, too far away, or not distinct [24]. Information from technology is therefore both the most important and most accurate. Yet, some question still remains about the form which technology can help us understand:

... the forms of substances I say (as they are now by compounding and transplanting multiplied) are so perplexed, as they are not to be inquired; no more than it were either possible or to purpose to seek in gross the forms of those sounds which make words, which by composition and transposition of letters are infinite. However, on the other side, to inquire the form of those sounds or voices which make simple letters easily comprehensible; and being known induceth and manifesteth the forms of all words, which consist and are compounded of them. In the same manner to inquire the form of a lion, of an oak, of gold; nay, of water, of air, is a vain pursuit; but to inquire the forms of sense, of voluntary motion, of vegetation, of colours, of gravity and levity, of density, of tenuity, of heat, of cold, and all other natural qualities, which, like an alphabet, are not many, and of which the essences (upheld by matter) of all creatures do consist; to inquire, I say, the true forms of these, is that part of metaphysic which we now define of. [25] (p. 91).

Through this description we see two types of forms emerging, those that are of natural bodies and are contingent, and those that are metaphysical, which are simple and eternal. In this way, Bacon maintains some of the transcendence of Plato and separates physics and metaphysics. Natural bodies are simply made up of various combinations of contingent forms, and nature, as a whole, is only one contingent possibility of which there could be other formulations.

Despite this separation between the physical and metaphysical form, it is, in contrast with Plato, the physical form that is most important for Bacon, because he emphasizes its utility. Man has the power to change nature to meet his own needs, and it is technology that allows him to understand nature and better manipulate the physical forms into new arrangements. Science becomes actually only a tool for the advancement of technology in the work of redesigning nature to better suit human needs. He says clearly that the first five parts of his work are subservient to the sixth, which is the technological project of reshaping nature [23]. Additionally, he sees technology and nature as the same from the perspective of form and essence: 
The artificial does not differ from the natural in form or essence, but only in the efficient, in that man has no power of nature except that of motion; he can put natural bodies together, and he can separate them; and therefore that wherever the case admits of uniting or disuniting of natural bodies, by joining (as they say) actives with passives, man can do everything; where the case does not admit this, he can do nothing. Nor matters it, provided things are put in the way to produce an effect, whether it be done by human means or otherwise. [23] (p. 427)

Conflating nature and technology in this way not only allows one to apply mechanical understanding to nature, but it also opens up the possibility of changing and manipulating nature in the same way that mechanical objects can be manipulated for human benefit. In the 1626 work New Atlantis [26], Bacon envisions using technology to manipulate nature to make life better for humans through projects such as increasing the human life span. Therefore, although we see some emphasis on nature informing the human mind through the senses in this version of empiricism, this leads only to the human as the one that manipulates nature from a privileged position. This privileged position of the human helps to cement an anthropocentric view of the subject. Overall, Bacon's work serves an important role in the transition from eidos, or form, to that of information, and from techne to technology.

\subsection{Rene Descartes' Disembodiment}

While Francis Bacon leveraged the concepts of information and technology for his empirical epistemology, René Descartes [27-29] was similarly adapting them in a different way for his rationalist epistemology in the mid-1600s. To better understand Descartes epistemological approach, some historical background is of help here. Plato's work influenced many church founders and ushered in an intense focus on the intelligible realm. For almost 1200 years after the closing of Plato's Academy, Western philosophy predominantly focused on the nature and existence of God. However, Galileo's use of the telescope at the beginning of the fifteenth century confirmed Copernicus' earlier theory that the Earth is not the center of the universe. This served to shake up very established views of the universe. Two years after the invention of the telescope, Kepler invented the double convex microscope, which opened up an entire microscopic world that we did not know existed. Everything European history had shown to be true was cast into doubt through these discoveries.

Yet, the epistemological acceptance of these technical instruments was not immediately assured. The instruments would need an epistemology that explained exactly what these new visions were that these tools offered, and why they might increase one's understanding of the world. Descartes was born in 1596, growing up in the midst of the turmoil caused by these inventions. Intervening in these discussions through his work on optics, Descartes ushered in much of modern philosophy, and especially epistemology. Further, his work signifies the shift from natural philosophy to many of the methods often still associated with contemporary science, such as the hypothetico-deductive method [30].

In many ways, Descartes' insistence on systematic doubt makes sense in light of this historical context. If a large swath of received knowledge from the entirety of recorded history can be thrown into doubt by the invention of the telescope and microscope within a short period, it seems natural to wonder exactly what it is that one might be able to have certainty about, if anything. These inventions clearly demonstrated that we cannot trust our natural, unaided senses as a method of deriving truth about the world [31]. Understanding how Descartes implemented this systematic doubt as part of his philosophy is important for grasping his development of the concept of substance. This concept is connected to the notion of information through its use by Aristotle, as well as his views on technology as they relate to his natural philosophy project that helps push the development of science into a type of inquiry separate from that of philosophy.

Bernard Stiegler [32] situates the beginning of the historical link between technics and objectivity with Descartes, who "constructs subjectivity as mastery over nature, where knowledge is the method whose instrument is technics," (p. 172). Technology provides 
Descartes with the necessary instruments for gaining information about nature as part of his work in the natural sciences. Although his work is sometimes taken as a strictly deductive system of science, he frequently uses physical experiments in works such as Optics and Meteorology, meaning that there is very little difference between rationalists and empiricists when it comes to the activity of science [30].

Descartes claims that the management of our lives depends on the senses, and primarily sight, so the inventions that augment them, such as telescopes, are extremely useful. This is possible because, for Descartes, the laws of mechanics are the same as those of nature [27]. Nature follows its own mechanical laws that can be understood through technics. Like Bacon, Descartes insists on the importance of utility for philosophy. Descartes [27] writes that these inventions "seem to have opened the way for us to attain a knowledge of nature much greater and more perfect than our fathers had," (p. 65). Yet, he also adds that the creation of telescopes hits the limits of what technology will be able to add to vision. Such a caveat is intriguing because while it carves out such an important place for technology, it also assumes that technology has already, in his own time, advanced as far as possible. Here his view of technology departs from Bacon, who instead envisions generations of technical improvement that will eventually lead to mastery over nature.

Despite this use of technology to master nature, Descartes inserts the concept of ideas between the direct perception of the intellect and nature as a form of representation [1]. For this reason, Descartes [27] must necessarily explain that it is the mind that senses rather than the body, because when in deep thought we lack sensation. Although technics are well situated to help us better understand and master nature, Descartes maintains this strict separation of the human subject from both nature and the technical instruments. Such a separation appears as part of his methodological project of doubt and plays an important part of his overall philosophic project. This also explains why, despite emphasizing the role of technology in developing knowledge, Descartes is nonetheless just as dismissive of craft as Aristotle and Plato. In Optics [27], Descartes develops the plans for the tools but leaves the actual creation of the tools he designs to the craftsmen.

Descartes, drawing on the same language of substance as Aristotle, explicitly separates the mind and body as two different substances. In Meditations on First Philosophy, Descartes [28] describes sitting near a campfire where he observes a piece of solid wax. He notes things such as its texture, its smell, and its color. As he moves the wax closer to the fire each of these properties changes as it becomes a liquid and loses its smell and color. Yet, we can all still understand this liquid thing as wax. Descartes concludes that the only thing that remains the same is extension-the fact that both versions of the wax take up space. It is the thinking mind that allows Descartes to understand this connection in the first place. Further, Descartes realizes that he can reasonably doubt the existence of all extended things, or bodily substances, including his own body. However, he cannot reasonably doubt the existence of his own mind, because without a mind he would not be able to doubt in the first place. If the body is doubtable but the mind is not, then they must ultimately be different things according to the principle of the indiscernibility of identicals, because one has a property that the other does not. Again borrowing on language that dates back to usage by Aristotle, Descartes posits that thought is the attribute of the mind, and extension the attribute of the body. This explanation of a fundamental ontological dualism fully entrenches the elevation of the mind over the materiality of the body.

Descartes therefore sees technology in much the same way as Bacon, with the notable difference that he uses the Aristotelian concept of substance to separate the mind and the body in a way that privileges the intellect over the material world. However, contrary to Bacon's emphasis on both physical and metaphysical forms, Descartes completely eliminates the concept: "To that end, let us expressly suppose that there is no form of earth, fire, or air, nor any other more particular form, such as the form of wood, stone or metal," [33] (p. 22). All that exists is matter that moves according the mechanical laws determined by God. In summary, while Descartes places a high emphasis on technology as a way to help us understand the world, he downplays the importance of technics; at the 
same time, his dualistic separation of mind and body provides a philosophic undergirding for later approaches to information as disembodied.

\subsection{David Hume and the Construction of the Subject}

David Hume [34], writing in the mid-1700s, takes the empiricism of Bacon and others and pushes it in a new direction, arguing that the information of the senses actually constructs the subject, breaking away from both rationalism and empiricism. This shift in the conceptualization of information makes a major step toward understanding the role of information in the process of subjectivation, and this argument will be used by Deleuze in developing his own theory of subjectivation. First, Hume distinguishes between matters of fact and relations of ideas. Relations of ideas are a priori knowledge, known analytically through reason alone, i.e., $3 \times 5=15$. Matters of fact are a posteriori knowledge and need to be observed empirically or derived synthetically. Matters of fact cannot prove relations of ideas and relations of ideas cannot prove matters of fact. This division between these two ways of knowing would later be dubbed Hume's Fork, emphasizing the impossibility of crossing between matters of fact and relations of ideas. For Hume, nothing can be both certain and about the world, so nothing in the world is certain. This conclusion also has drastic consequences for induction; knowledge of unobserved matters cannot be derived $a$ priori, yet this is the goal of induction. Eliminating induction as a path to knowledge would also remove many of tools of the scientific method and its related processes as they are commonly understood by both rationalists and other empiricists.

How does Hume develop this hypothesis? He begins with impressions, which are the flow of information from the senses. These are distinguished from ideas, which are created by the thinking mind based upon impressions: "By the term impression, then, I mean all our more lively perceptions, when we hear, or see, or feel, or love, or hate, or desire, or will. Additionally, impressions are distinguished from ideas, which are the less lively perceptions, of which we are conscious, when we reflect on any of those sensations or movements above mentioned." [34] (p. 10) This means that matters of fact cannot be proven true because we cannot observe the future; matters of fact rely on cause and effect, which are discoverable only by experience and cannot be known a priori. We have no reason to presume that because an object has behaved in a certain way in the past that it will continue to behave that way in the future. Within this system, information becomes epistemologically untethered from an ontological reality. There are not forms that exist out there, either physically or metaphysically, that we can know. Instead, we experience only a subjective flux of images that are in-formation, or rather, information: "Additionally, as the power, by which one object produces another, is never discoverable merely from their idea, 'tis evident cause and effect are relations, of which we receive information from experience, and not from any abstract reasoning or experience," [34] (p. 96, emphasis original). Through this framework we can see that the contrary of every matter of fact is possible.

Rather than using the intellect to come to know forms, we instead create beliefs through the constant conjunction of experiences as a form of habits. Although these habits of belief can never be known with certainty, for Hume, they still provide a very good guide for one to use in thinking about how to live life or how to conduct science. Deleuze [35] characterizes this system of empiricism not as a philosophy of senses, but of the imagination, because the constant correction of the imagination is the task of understanding. The world is a fiction of the imagination. More importantly, for Deleuze and Simondon, Hume's empiricism raises the problem of the creation of the subject rather than the origin of the mind: the mind is subjected. What is given is the flux of the sensible as informationeverything that appears. "This confirms the idea that subjectivity is in fact a process, and that an inventory must be made of the diverse moments of this process. To speak like Bergson, let us say the subject is an imprint, or an impression, left by principles, that it progressively turns into a machine capable of using this impression," [35] (p. 113). Or put more simply: "Subjectivity is then an impression of reflection and nothing else," (p. 113). 
Deleuze finds this helpful because he can use Hume's understanding of impressions to explain the process that generates subjectivity, as opposed to Heidegger's phenomenology which still requires an original, unexplained subject.

Though Hume himself did not write widely on technics or technology, he opens the path back to technology through information as the impression of sensation:

Another advantage of industry and of refinements in the mechanical arts, is, that they commonly produce some refinements in the liberal arts; nor can one be carried to perfection, without being accompanied, in some degree, with the other. The same age, which produces great philosophers and politicians, renowned generals and poets, usually abounds with skillful weavers and ship-carpenters. We cannot reasonably expect, that a piece of woolen cloth will be wrought to perfection in a nation, which is ignorant of astronomy, or where ethics are neglected [36] (p. 107).

Hume here links the techne of the mechanical arts to the production of great philosophers and politicians, at the very minimum suggesting that the mechanical arts inform the subject. A.M.C. Waterman [37] explains that this is likely one of the earliest arguments made for the causal connection between technology and culture, though Hume is lacking that precise language at the time of his writing. Instead, he refers frequently to the idea of a state of productive technique subject to change. Unfortunately, this association between technology and culture is not explained or expanded upon by Hume in any of his other writings. However, we do get a brief glimpse of how this connection arises: "the two are held together in any particular state of society created by the interaction of all the elements I have identified [general principles, contingency, human nature, reason, passions, selfinterest, unintended consequences, monarchy/republic, civil liberty, commerce, luxury, agricultural surplus, technology, and culture]. This state Hume called 'the spirit of the age'." [37] (p. 59, emphasis original). The technology that in part derives the spirit of the age thus also can be seen to inform the subject.

This solidifies a distinct break with both the rationalism of Descartes and the empiricism of Bacon. Descartes' dual mind/body substances, like Bacon's physical and metaphysical forms, are eliminated. Instead, a flux of always changing information itself, potentially always already altered by technics, constructs the subject. For Hume, information means only our sensory input-what we see, hear, smell, touch or taste. Everything we know is constructed from this flow of information by our senses. It is upon Hume, then, that both Simondon and Deleuze will draw for inspiration in the construction of their informational ontology. However, it is through Foucault that technics is most closely linked with processes of subjectivation.

\subsection{Bureaucracy, Statistics, and Cybernetics}

Before understanding how Foucault is able to link technics to processes of subjectivation, there is one last major shift in the understanding of information. The form of statistical analysis that arises as part of bureaucratic systems in the 18th and 19th centuries pushes information beyond the bounds of a single human mind's sense perception and allows one to "know something that they can never experience for themselves," [1] (p. 15). This was also facilitated by the technical capacity to transmit data electrically via telegraph in order to gather reports from distant sites, pool them in a central office, analyze the data, and then return the report to the peripheries. Statistics, Peters argues, fuel a bureaucratic explosion that allows the nation itself to become a knower, as opposed to a single individual; further, thanks to increased scale, this knower can now see things such as weather and rates of birth and death that were formerly imperceptible. Peters [1] explains: "whereas in empiricism, information was nearly synonymous with sense experience, it comes with the growth of bureaucracies to mean knowledge beyond the range of one's experience," (p. 15, emphasis original). With this shift, information is firmly removed from the scale of the individual and understood instead as something exterior, something out there. The state is now able 
to use information in the process of managing both people and property. Information itself, then, begins to be understood as a means of control.

The field of cybernetics pushes this notion of control through information to its full consequences. Norbert Weiner [38] coined the term in his 1948 book, Cybernetics; or, Control and Communication in the Animal and the Machine, drawing inspiration from the Greek word kybernan, meaning to steer or navigate [39]. Ashby [40], writing An Introduction to Cybernetics in 1956, explains that materiality is irrelevant for cybernetics, drawing on an analogy to geometry. Just as geometry is not concerned with whether the forms and spaces it analyzes are in fact actualized, cybernetics is not concerned with whether the machines it considers actually exist, instead taking as its subject all possible machines. Methodologically, the research question emphasizes all possible behaviors for a machine, thus connecting cybernetics to information theory, which from this perspective, deals precisely with the set of possibilities. Ashby [40] offers the following example:

Two soldiers are taken prisoner by two enemy countries A and B, one by each; and their two wives later each receive a brief message "I am well". It is known, however, that country A allows the prisoner a choice from

I am well,

I am slightly ill,

I am seriously ill,

while country B allows only the message

I am well

meaning "I am alive". (Additionally, in the set is the possibility of "no message").

The two wives will certainly be aware that although each has received the same

phrase, the information that they have received are by no means identical (p. 124, emphasis original).

This example illustrates the importance of shifting one's attention away from the message itself toward the larger set of possibilities afforded by the framework of information theory. This crucial link between the machines of cybernetic theory and the set of possibilities in information theory links together technology and information with the goal of controlling nature, expanding the vision of Bacon and Descartes for using technology to control nature. It also de-links information from the physical, technical media/machines used for calculations.

This Cartesian philosophical cleaving of the mind from the body, extending the work of Plato, paves the way for a practical understanding of a conception of being human that does not require embodiment. The coming of the computer age facilitated new ways to conceive of the possibility for the mind, or intelligence, to be separated from an original body through fantasies such as downloading a brain directly to a computer. The Turing test, created in an attempt to determine whether or not a machine had achieved artificial intelligence, erased embodiment by focusing on "the formal generation and manipulation of information patterns," [20] (p. xi). Formal communication models followed this same formula:

Aiding this process was a definition of information, formalized by Claude Shannon and Norbert Wiener, that conceptualized information as an entity distinct from the substrate carrying it. From this formulation, it was a small step to think of information as a kind of bodiless fluid that could flow between different substrates without loss of meaning or form. Writing nearly four decades after Turing, Hans Moravec proposed that human identity is essentially an informational pattern rather than embodied enaction [20] (pp. xi-xii).

When human identity can be characterized as an informational pattern, it is only a small Cartesian leap to imagine separating this information from its body. The dominant philosophic tradition of separating the mind from the body, combined with a digital interpretation of information as ones and zeroes, ultimately enabled a conception of information to develop that sheds the need for any requirement of embodiment. This also links information to the Platonic concept of Eidos, in which the information (or the form) is more 
important that the physicality of matter. For example, the information of a mind might be transferred from a brain to a hard drive without change or loss. It is the information pattern-the form-that is most important.

This cybernetic framework for control is at the forefront of the technological explosion that has shaped the Information Age: "modern technics is dominated by cybernetics as the science of organization, in the largest sense, going back to the organum as instrumental to organization as characteristic of life," [6] (p. 23, emphasis original). Just as Plato's Forms organized reality by partaking in matter to form it, information can now be seen to serve a similar organizational role. It is through cybernetics that information and technology, eidos and techne, are clearly linked, due in large part to the immaterial and essentialized conception of information. Information is used to exert control. Passwords are the codes that that indicate whether access should be allowed or denied. Deleuze [41] characterizes these changes as moving away from a disciplinary society that relies on confinement and toward the control society that relies on continuous control and instant communication.

This statistical model of cybernetics has been extended to the present day into the predominant social physics model of big data as a form of prediction and control. In 2014, Alex Pentland [42] likened his work with big data as a way to understand social dynamicsa socio-scope-to the invention of the microscope and telescope that opened up a new way of understanding the universe in the 17th century. Now, instead of using the technics of microscopes and telescopes to gain mastery over nature, the socio-scope functions as a technics that gains mastery over the behavior of humans, at least for those who are in a position to make use of it, as Andrejevic [43] warns. With this connection in mind, we can now shift to Foucault, who offers a different way to understand the relationship between techne and eidos that focuses on processes of subjectivation rather than control.

\subsection{Michel Foucault and Subjectivation}

Michel Foucault, writing and lecturing between the 1950s and 1980s, uses the concept of technology much more broadly than it is traditionally used, focusing on it as an activity or skill in a way that is similar to the Greek techne. [44-47]. "In French, the words 'technologie' and 'technique' are used more or less interchangeably to refer to technology, with the latter term being somewhat more general and more often applied to technologies that pre-date industrialization," [48] (p. 22). Foucault uses the term 'technique' most frequently in his earlier work, while his later lectures at the College of France tend to make use of the term technology as part of his exploration of the ideas of technologies of power and technologies of self. Michael Behrent notes that Foucault also uses these terms interchangeably such as in his lecture La Société Disciplinaire en Crise: "My research deals with techniques of power, with the technology of power," (as quoted in [49], p. 59, emphasis original). This connection between technique and technology makes clear a theoretical link between Foucault's earlier work and his later lectures.

This link is noted most clearly in Archaeology of Knowledge [50], where Foucault notes toward the end of the book that his discussion on the relation of knowledge to discourse could be expanded to include even more discursive practices. He explicitly notes the practice of painting as an example, connecting techniques/technologies to a form of knowledge: "In this sense, the painting is not a pure vision that must then be transcribed into the materiality of space; nor is it a naked gesture whose silent and eternally empty meanings must be freed from subsequent interpretations. It is shot through — and independently of scientific knowledge (connaissance) and philosophical themes-with the positivity of a knowledge (savoir)," [50] (p. 214). In this link we can see echoes of the way that Sophists conceptualized techne.

In his lectures at the College of France, Foucault [51] elaborates on several types of technologies, including production, sign systems, power, and self. He offers an example of this connection between [52] power and technology, arguing that: "discipline seems to me to be this technology, specific to the power that is born and develops from the classical age, and which, on the basis of this game of bodies, isolates and cuts out what 
I think is an historically new element that we call the individual," (p. 57). We see here how he links "the technology of discipline to a certain conception of man through its co-construction of the subject with the body, which necessarily asserts the contingent so-called essence of man," [11]. Discipline plays an important role in Foucault's future work, including through the Panopticon as a technology in Discipline and Punish [53] to the power techniques employed by the sexual apparatus in The History of Sexuality 1: The Will to Knowledge [54]. Both of these offer examples in which technology/techniques can be used to shape the individuals in particular ways through processes of subjectivation. Or, drawing on early language, we might say that the technology in-forms the subject, which is ultimately contingent in nature, lacking any pre-defined essence.

The influence of techniques on our processes of subjectivation become even more explicit as Foucault [55] develops the concept of biopower in his 1978 and 1979 College of France lectures. This work undertakes "a history of technologies of security, highlighting in particular the correlation between the techniques of security and population that gave rise to the modern concept of population. This represents the extension of study from the discipline of bodies to regulation of populations," [11]. This connection between techniques and population regulation provides the needed opening to understand Foucault's conceptualization of information, which is less present in his work. Peters [1] argues "people who, thanks to statistics, 'see' something intellectually they could not see sensually, are put in a curious position. They know something that the can never experience for themselves," (p. 15). Biopolitics, in other words, is the managing of populations through statistical information. Peters [1] notes that this management is put into practice through the variety of forms that are required to exist in contemporary society, from application forms to tax forms. These forms are in-forming us, shaping our processes of subjectivation through the bureaucracy and policies that they generate.

Following his exploration of technologies of power, Foucault moves on to technologies of the self, beginning with his Subjectivity and Truth [56] lectures, which are eventually revised and published as The History of Sexuality 3 [57]. Moving beyond a focus on government by the state, Foucault [58] instead explores how one's self-government, or self-care, also contributes to one's creation as a subject. Foucault outlines "a variety of ways that one can examine one's own conscience, which include the nature of the examination, the objective, and the instruments, showing how both the Greco-Romans and Christians used these tools in a unique manner," [11]. Examples of these instruments, or tools of examination include concentration, memory, virtual discourse, confession, and writing for oneself or others. However, Foucault is also clear that there are additional tools not included in his list. Stiegler's [6] work on memory and Kittler's [59] exploration of verbalization and writing in German literature offer work that could be understood as expanding the analysis of such tools as they impact the creation of the self.

Foucault's remaining work focuses on exploring how these tools shape our processes of subjectivation. "What becomes clear through this extended exploration of subjectivity, and of utmost importance for our understanding of the role of technology in this process, is how large of a role the technologies of the self play in the process of subjectivation," [11]. For Foucault [60], this shifts the way we understand the contemporary problematic. The challenge is no longer working to liberate individuals from oppressive forms of government, but instead exploring and creating new forms of subjectivity. Rosi Braidotti's [61] posthumanist ethics adopts this call to experimentation as its primary tenant. Interpreting Foucault in this way connects him to Deleuze's Spinozan-inspired imperative to discover what a body can do.

The Government of Self and Others [62] and The Courage of Truth [63] lectures make this connection even more apparent. Foucault argues that philosophy must put itself to the test of practices. "For Foucault, the Cynics offer a rare example of living life as a test, as a form of praxis or aesthetics of existence. In the Cynic's constituting of himself as a spectacle, this is a way to confront other individuals with their own contradictions. In this way, the Cynic's self-care also becomes a care for the world," [11]. With this emphasis on 
experimentation, the technologies/techniques of the self inform the subject as they alter our processes of subjectivation. These processes are not simply enacted on us by outside governments, but can also be shaped by our own experiments of self-governance. Perhaps most importantly, technologies of the self can also encompass contemporary information technologies. Experimenting with one's own processes of subjectivation could, therefore, include using such technologies in new ways, or even experimenting with new approaches to the way we conceptualize such technologies and their relationship to information.

\section{Discussion}

Through this genealogy, we have seen that the way each philosophic system theorizes the concepts of techne / technology and form/information is closely related to both the metaphysics and epistemology of that system. In other words, the conceptualization of information and technology that underlies our thinking shapes our systems of knowledge and how we understand the world. This sheds new light on the ways we are being shaped by contemporary information technology practices.

The concept of information plays an increasingly important role in the work being done in a wide variety fields, ranging from engineering and biology to communication and philosophy. Although cybernetic definitions of information have varied throughout different waves of cybernetic thinking, information has been identified as the predominant element of organization for systems. In molecular biology, information is seen as negentropic, which explains how systems retain their organization despite surrounding entropic forces. Tiziana Terrenova [64] links this tendency to the identification of information with DNA. This shift makes information both hylomorphic because it contains form and matter, and neo-Platonic, because life is understood as the expression of a pattern which can be replicated in more than one medium. Through this connection, information has also come to be understood as a central concept that has pushed society past industrialization and into an "information society" that, arguably, renders traditional Marxist theory outdated $[65,66]$. However, some present-day autonomous Marxists are rethinking Marxist theory for the Information Age around the concepts of immaterial labor, the general intellect, and a-signifying subjectivation [67-72]. These processes of subjectivation are the forces responsible for one's construction as a subject. Despite these efforts, information has largely remained part of the discursive constructionism paradigm that was predominant in media and cultural studies throughout the 1990s. This paradigm is focused narrowly on the role of discourse in human affairs and tended to downplay the role of information because it existed outside of signification. Other scholars have critiqued the discursive constructionist paradigm, outlining paths for analyzing materiality and affect [20,64,73-77].

This analysis can also help facilitate interdisciplinary work and approaches to information. While the fields of communication and media studies remain largely focused on the classical information theory of Claude Shannon, physics has embraced a framework of quantum information within which Rolf Landauer declared that 'information is physical.' $[2,10,78]$. By better understanding the philosophic genealogy of the concepts of information and technics, one can better understand how work in the humanities and social sciences can be linked to contemporary concepts in the sciences, such as quantum information. Recent scholarship around the work of Karen Barad and Gilbert Simondon offers examples of how bridges between these disciplines might be constructed $[79,80]$. This genealogical analysis offers the opportunity for future work to connect the broader philosophic history of information and technics to the latest contemporary frameworks of information and technology.

By exploring the various ways that technics and information have been understood in the history of philosophy, future research is well situated to explicate an alternative understanding of these concepts that will offer opportunities for new ways of thinking about media and technology. Further analysis could explore how emerging quantum approaches that understand information as physical fit within this historical genealogical analysis [10]. Additionally, this analysis opens new strategies for rethinking informational ontology 
and the role it plays in communication and media studies [22,81]. In this genealogy, we have seen how the work of David Hume and Michel Foucault in many ways harkens back to an understanding of techne that existed when philosophers and Sophists first began to distinguish themselves from one another. Future work might connect these ideas of technics to posthuman approaches to technology and media studies that explore what it means to be human. Alternatively, new ways of thinking about information might lead to alternative conceptualizations and methods that can be applied to big data in ways that escape the resource doctrine of information.

Funding: This research received no external funding.

Institutional Review Board Statement: Not applicable.

Informed Consent Statement: Not applicable.

Data Availability Statement: Data sharing not applicable.

Conflicts of Interest: The author declares no conflict of interest.

\section{References}

1. Peters, J.D. Information: Notes Toward a Critical History. J. Commun. Inq. 1988, 12, 9-23. [CrossRef]

2. Shannon, C.E.; Weaver, W. The Mathematical Theory of Communication; University of Illinois Press: Urbana, IL, USA, 1949; ISBN 978-0-252-72548-7.

3. Capurro, R. Past, present, and future of the concept of information. TripleC 2009, 7, 125-141. [CrossRef]

4. Behrenshausen, B. Information in Formation: Power and Agency in Contemporary Informatic Assemblages; University of North Carolina: Chapel Hill, NC, USA, 2016.

5. Balnaves, M.; Willson, M.A. A New Theory of Information and the Internet: Public Sphere Meets Protocol; Digital Formations; Peter Lang: New York, NY, USA, 2011; ISBN 978-1-4331-1062-7.

6. Stiegler, B. Technics and Time 1: The Fault of Epimetheus; Meridian; Stanford University Press: Stanford, CA, USA, 1994; ISBN 978-0-8047-3040-2.

7. Yourgrau, P. Death and Nonexistence; Oxford University Press: Oxford, UK, 1987; ISBN 978-0-691-07317-0.

8. Sauvagnargues, A. Artmachines: Deleuze, Guattari, Simondon; Edinburgh University Press: Edinburgh, UK, 2016; ISBN 978-1-47440253-8.

9. Tamboukou, M. Writing genealogies: An exploration of foucault's strategies for doing research. Discourse Stud. Cult. Politics Educ. 1999, 20, 201-217. [CrossRef]

10. Landauer, R. Information is physical. Phys. Today 2008, 44, 23. [CrossRef]

11. Sylvia, J.J. From archaeology to genealogy: Adding processes of subjectivation and artistic intervention. Communication $2019,7$. [CrossRef]

12. Monea, A.; Packer, J. Media geneaology and the politics of archaeology. Int. J. Commun. 2016, 10, 3141-3159.

13. Dean, M. Critical and Effective Histories: Foucault's Methods and Historical Sociology; Routledge: London, UK; New York, NY, USA, 1994; ISBN 978-0-415-06494-1.

14. Bizzell, P.; Herzberg, B. (Eds.) The Rhetorical Tradition: Readings from Classical Times to the Present, 2nd ed.; Bedford/St. Martin's: Boston, MA, USA, 2001; ISBN 978-0-312-14839-3.

15. Schiappa, E. Protagoras and Logos: A Study in Greek Philosophy and Rhetoric, 2nd ed.; Studies in Rhetoric/Communication; University of South Carolina Press: Columbia, SC, USA, 2003; ISBN 978-1-57003-521-0.

16. Hamilton, E.; Cairns, H. (Eds.) The Collected Dialogues of Plato: Including the Letters, 16th ed.; Bollingen Series; Princeton University Press: Princeton, NJ, USA, 1996; ISBN 978-0-691-09718-3.

17. Roochnik, D. Of Art and Wisdom: Plato's Understanding of Techne; Pennsylvania State University: State College, PA, USA, 1996; ISBN 978-0-271-03273-3.

18. Silverman, A.J. The Dialectic of Essence: A Study of Plato's Metaphysics; Princeton University Press: Princeton, NJ, USA, 2002; ISBN 978-1-4008-2534-9.

19. Deleuze, G. Difference and Repetition; Columbia University Press: New York, NY, USA, 1968; ISBN 978-0-231-08158-0.

20. Hayles, K. How We Became Posthuman: Virtual Bodies in Cybernetics, Literature, and Informatics; University of Chicago Press: Chicago, IL, USA, 1999; ISBN 978-0-226-32145-5.

21. Manning, G. The history of "hylomorphism". J. Hist. Ideas 2013, 74, 173-187. [CrossRef]

22. Iliadis, A. Informational Ontology: The Meaning of Gilbert Simondon's Concept of Individuation. Available online: http: / / scholarworks.umass.edu/cgi/viewcontent.cgi?article=1015\&context=cpo (accessed on 28 March 2016).

23. Bacon, F. The Philosophical Works of Francis Bacon, Baron of Verulam, Viscount St. Albans, and Lord High Chancellor of England; George Routledge and Sons Limited: London, UK; New York, NY, USA, 1620. 
24. Bacon, F. Novum Organum: True Suggestions for the Interpretation of Nature; Jürgen Beck Jazzybee Publisher: Mumbai, India, 1620; ISBN 978-3-8496-9208-7.

25. Bacon, F. The Advancement of Learning; Paul Dry Books: Philadelphia, PA, USA, 1605; ISBN 978-0-9664913-6-4.

26. Bacon, F. The Great Instauration; and, New Atlantis; Crofts Classics; Harlan Davidson: Arlington Heights, IL, USA, 1627; ISBN 978-0-88295-115-7.

27. Descartes, R. Discourse on Method, Optics, Geometry, and Meteorology, Revised ed.; Hackett Pub.: Indianapolis, IN, USA, 1637; ISBN 978-0-87220-568-0.

28. Descartes, R. Meditations on First Philosophy: In Which the Existence of God and the Distinction of the Soul from the Body Are Demonstrated, 3rd ed.; Hackett Pub. Co.: Indianapolis, IN, USA, 1641; ISBN 978-0-87220-192-7.

29. Descartes, R. The Principles of Philosophy; Kessinger Pub.: Whitefish, MT, USA, 1644; ISBN 978-1-169-22256-4.

30. Olscamp, P. Introduction. In Discourse on Method, Optics, Geometry, and Meteorology; Bobbs-Merrill: Indianapolis, IN, USA, 2001.

31. Barrett, R. Alientation from the cartesian change in the meaning of truth. In The Hannah Arendt Center for Politics and Humanities at Bard College; Hannah Arendt Center for Politics and Humanities at Bard College: Annandale-On-Hudson, NY, USA, 2014; Available online: https:/ / hac.bard.edu/amor-mundi/alienation-from-the-cartesian-change-in-the-meaning-of-truth-2014-09-01 (accessed on 10 March 2021).

32. Stiegler, B. Technics and Time, 3: Cinematic Time and the Question of Malaise; Meridian, Crossing Aesthetics; Stanford University Press: Stanford, CA, USA, 2001; ISBN 978-0-8047-6167-3.

33. Descartes, R. The World and Other Writings; Cambridge Texts in the History of Philosophy; Gaukroger, S., Ed.; Cambridge University Press: Cambridge, UK; New York, NY, USA, 1662; ISBN 978-0-521-63158-7.

34. Hume, D. An Inquiry Concerning Human Understanding; Macmillan: New York, NY, USA, 1748.

35. Deleuze, G. Empiricism and Subjectivity: An Essay on Hume's Theory of Human Nature; European Perspectives; Columbia University Press: New York, NY, USA, 1953; ISBN 978-0-231-06813-0.

36. Hume, D. Political Essays; Cambridge Texts in the History of Political Thought; Haakonssen, K., Ed.; Cambridge University Press: Cambridge, UK; New York, NY, USA, 1752; ISBN 978-0-521-46093-4.

37. Waterman, A.M.C. David Hume on Technology and Culture. Hist. Econ. Rev. 1998, 28, 46-61. [CrossRef]

38. Wiener, N. Cybernetics or Control and Communication in the Animal and the Machine, 2nd ed.; 14th print; MIT Press: Cambridge, MA, USA, 2007; ISBN 978-0-262-73009-9.

39. Rid, T. Rise of the Machines: A Cybernetic History, 1st ed.; W. W. Norton \& Company: New York, NY, USA, 2016; ISBN 978-0-39328600-7.

40. Ashby, W.R. An Introduction to Cybernetics; Martino Publishing: Mansfield Centre, CT, USA, 1956.

41. Deleuze, G. Negotiations, 1972-1990; Columbia University Press: New York, NY, USA, 1990; ISBN 978-0-231-07580-0.

42. Pentland, A. Social Physics: How Social Networks Can Make Us Smarter; Published with a new preface; Penguin Books: New York, NY, USA, 2014; ISBN 978-0-14-312633-1.

43. Andrejevic, M. Infoglut: How Too Much Information Is Changing the Way We Think and Know; Routledge: New York, NY, USA, 2013; ISBN 978-0-415-65907-9.

44. Gerrie, J. Was Foucault a philosopher of technology? Techné Res. Philos. Technol. 2003, 7, 66-73. [CrossRef]

45. Packer, J. The conditions of media's possibility: A Foucauldian approach to media history. In The International Encyclopedia of Media Studies; Blackwell Publishing Ltd.: Oxford, UK, 2012; ISBN 978-1-4051-9356-6.

46. Mitcham, C. Thinking through Technology: The Path between Engineering and Philosophy; University of Chicago Press: Chicago, IL, USA, 1994; ISBN 978-0-226-53196-0.

47. Foucault, M. The Essential Works of Foucault, 1954-1984; Rabinow, P., Ed.; New Press: New York, NY, USA, 1997; ISBN 978-1-56584352-3.

48. Chabot, P. The Philosophy of Simondon: Between Technology and Individuation; Bloomsbury Academic: London, UK, 2013; ISBN 978-1-78093-032-9.

49. Behrent, M.C. Foucault and Technology. Hist. Technol. 2013, 29, 54-104. [CrossRef]

50. Foucault, M. The Archaeology of Knowledge; Pantheon Books: New York, NY, USA, 1969; ISBN 978-0-394-71106-5.

51. Foucault, M. Society Must Be Defended: Lectures at the Collège de France, 1975-1976, 1st Picador pbk. ed.; Bertani, M., Fontana, A., Ewald, F., Eds.; Picador: New York, NY, USA, 1997; ISBN 978-0-312-42266-0.

52. Foucault, M. Psychiatric Power: Lectures at the Collège de France, 1973-1974, 1st Picador ed.; Lextures at the Collège de France; Lagrange, J., Ed.; Picador: New York, NY, USA, 2003; ISBN 978-0-312-20331-3.

53. Foucault, M. Discipline and Punish: The Birth of the Prison, 2nd Vintage Books ed.; Vintage Books: New York, NY, USA, 1975; ISBN 978-0-679-75255-4.

54. Foucault, M. The History of Sexuality Vol. 1: The History of Sexuality, Vintage Books ed.; Vintage Books: New York, NY, USA, 1976; ISBN 978-0-679-72469-8.

55. Foucault, M. The Birth of Biopolitics: Lectures at the Collège de France, 1978-1979, 1st pbk ed.; Lectures at the Collège de France; Senellart, M., Ed.; Picador: New York, NY, USA, 2004; ISBN 978-0-312-20341-2.

56. Foucault, M.; Gros, F.; Ewald, F.; Fontana, A.; Burchell, G.; Davidson, A.I. Subjectivity and Truth: Lectures at the College de France, 1980-1981; Springer: Berlin/Heidelberg, Germany, 2019; ISBN 978-1-250-19508-1. 
57. Foucault, M. The History of Sexuality Vol. 3: The Care of the Self, Vintage Books ed.; Vintage Books: New York, NY, USA, 1984; ISBN 978-0-394-74155-0.

58. Foucault, M. On the Government of the Living: Lectures at the Collège de France, 1979-1980; Senellart, M., Ewald, F., Fontana, A., Eds.; Springer: Berlin/Heidelberg, Germany, 2014; ISBN 978-1-250-08161-2.

59. Kittler, F.A. Discourse Networks 1800/1900; Stanford University Press: Stanford, CA, USA, 1985; ISBN 978-0-8047-2099-1.

60. Foucault, M. The Hermeneutics of the Subject: Lectures at the College de France, 1981-1982, 1st ed.; Lectures at the Collège de France; Gros, F., Ed.; Picador: New York, NY, USA, 2001; ISBN 978-0-312-42570-8.

61. Braidotti, R. The Posthuman; Polity Press: Cambridge, UK; Malden, MA, USA, 2013; ISBN 978-0-7456-4157-7.

62. Foucault, M. The Government of Self and Others: Lecture at the Collège de France 1982-1983; Gros, F., Ed.; Macmillan: New York, NY, USA, 2008; ISBN 978-0-312-57292-1.

63. Foucault, M. The Courage of Truth (the Government of Self and Others II): Lectures at the Collège de France, 1983-1984; Picador: New York, NY, USA; Palgrave Macmillan: London, UK, 2008; ISBN 978-1-250-00910-4.

64. Terranova, T. The concept of information. Theory Cult. Soc. 2006, 23, 286-288. [CrossRef]

65. Bell, D. The Cultural Contradictions of Capitalism, 20th anniversary ed./with a New Afterword by the Author; Basic Books: New York, NY, USA, 1996; ISBN 978-0-465-01499-6.

66. Castells, M. The Rise of the Network Society; Information Age; Blackwell Publishers: Malden, MA, USA, 1996; ISBN 978-1-55786617-2.

67. Hardt, M.; Negri, A. Commonwealth; Belknap Press of Harvard University Press: Cambridge, MA, USA, 2011; ISBN 978-0-67406028-9.

68. Hardt, M.; Negri, A. Empire, 13th ed.; Harvard University Press: Cambridge, MA, USA, 2003; ISBN 978-0-674-00671-3.

69. Hardt, M.; Negri, A. Multitude: War and Democracy in the Age of Empire; Penguin Books: New York, NY, USA, 2005; ISBN 978-0-14-303559-6.

70. Berardi, F.B. After the Future; Genosko, G., Thoburn, N., Eds.; AK Press: Oakland, CA, USA, 2011; ISBN 978-1-84935-059-4.

71. Berardi, F. Heroes: Mass Murder and Suicide; Verso: London, UK; New York, NY, USA, 2015; ISBN 978-1-78168-577-8.

72. Lazzarato, M. Signs and Machines: Capitalism and the Production of Subjectivity; Semiotext(e) Foreign Agents Series; Semiotext(e): Los Angeles, CA, USA, 2014; ISBN 978-1-58435-130-6.

73. Grossberg, L. We Gotta Get out of This Place: Popular Conservatism and Postmodern Culture; Routledge: New York, NY, USA, 1992; ISBN 978-0-415-90329-5.

74. Grossberg, L. Cultural studies vs. political economy: Is anybody else bored with this debate? Crit. Stud. Mass Commun. 1995, 12, 72-81. [CrossRef]

75. Grossberg, L. Dancing in Spite of Myself: Essays on Popular Culture; Duke University Press: Durham, NC, USA, 1997; ISBN 978-0-8223-1912-2.

76. Grossberg, L. (Re)Con-Figuring space: Defining a project. Space Cult. 1999, 2, 13-22. [CrossRef]

77. Grossberg, L. Cultural Studies in the Future Tense; Duke University Press: Durham, NC, USA, 2010; ISBN 978-0-8223-4844-3.

78. Nielsen, M.A.; Chuang, I.L. Quantum Computation and Quantum Information, 10th anniversary ed.; Cambridge University Press: Cambridge, UK; New York, NY, USA, 2010; ISBN 978-1-107-00217-3.

79. Barad, K.M. Meeting the Universe Halfway: Quantum Physics and the Entanglement of Matter and Meaning; Duke University Press: Durham, NC, USA, 2007; ISBN 978-0-8223-3901-4.

80. Simondon, G. Individuation in Light of Notions of Form and Information; Posthumanities; University of Minnesota Press: Minneapolis, MN, USA, 2020; ISBN 978-0-8166-8001-6.

81. Sylvia, J.J., IV. From form to in-formation: A Spinozan link between Deleuzian and Simondonian ontologies. Deleuze Guattari Stud. 2021, in press. 